Research Article

\title{
Protection for DC Distribution System with Distributed Generator
}

\author{
Shimin Xue, ${ }^{1}$ Chaochao Chen, ${ }^{1}$ Yi Jin, ${ }^{1}$ Yongli Li, ${ }^{1}$ Botong Li, ${ }^{1}$ and Ying Wang ${ }^{2}$ \\ ${ }^{1}$ Key Laboratory of Smart Grid of Ministry of Education, Tianjin University, Tianjin 300072, China \\ ${ }^{2}$ Dispatching and Control Center of Tianjin Electric Power Corporation, Tianjin 300010, China
}

Correspondence should be addressed to Shimin Xue; xsm@tju.edu.cn

Received 23 January 2014; Revised 9 May 2014; Accepted 12 May 2014; Published 17 June 2014

Academic Editor: Hongjie Jia

Copyright (C) 2014 Shimin Xue et al. This is an open access article distributed under the Creative Commons Attribution License, which permits unrestricted use, distribution, and reproduction in any medium, provided the original work is properly cited.

DC distribution system has advantages of high power quality, large transmission capacity, high reliability, simple structure, economy and low energy consumption, and so forth. It has been a key part of smart grid nowadays. However, the development of DC distribution system is constrained by the lack of operational experience in DC system, the small interrupting capacity of DC circuit breaker $(\mathrm{CB})$, and the lack of protection schemes for system itself. In this paper, protection for DC distribution system with distributed generator (DG) is fully investigated and verified. Firstly, the electromagnetic transient model of DC distribution system with DG is presented. Simulation based on the electromagnetic transient model is carried out. Both the step response and the steady-state performance verify the accuracy of the model. Then the fault characteristic mechanism is analyzed, and the protection principles and scheme are investigated in detail, including voltage mutation principle as protection starting component, differential current protection principle for DC bus, and two-section current protection for distribution lines. Finally, transient responses with protection scheme are analyzed during faults. The results present that the protection principles and scheme are feasible for DC distribution system with DG.

\section{Introduction}

Smart grid is an exciting development of power systems worldwide. It is also one of the scientific and technological innovations in the 21th century [1]. The development mainly lies in the distribution system. Lots of researches are being carried out in the field of smart distribution system around the world.

Meanwhile, more and more electrical equipment, based on electronic products, are consuming direct current (DC), such as LED lamps, mobile phones, liquid crystal monitors, computers, and electric vehicles. Aiming to be more efficient, frequency conversion technology has been widely used in household and industrial loads. These loads can be regarded as indirect DC loads because of the DC link in the converters. At the same time, more and more distributed generators (DGs) are using renewable energy sources and generating DC electricity, such as photovoltaic generator and fuel cell generator. A DC link still exists in other types of DGs, such as microturbine and wind power system. Hence, it will greatly improve the efficiency and reduce the loss of power conversion by using a DC system to distribute the power. With the rapid development of modern power electronic technology, commutation components are mature enough to work smoothly in DC distribution system. Therefore, DC distribution system based on pulse width modulation (PWM) technology is becoming a promising structure. It has many advantages, like high power quality, large transmission capacity, high reliability, simple structure, economy, low energy consumption, and so on [2-6]. Particularly, it can be well adapted to the connection of DGs and promote the development of DC appliances. This is very essential for solving environmental pollution and energy depletion problems. Therefore, DC distribution system has a broad application prospect of smart distribution system in the future.

However, relay protection technology, one of the key technologies of the development of DC distribution system, still stays in its infancy. Till now, experts have been actively engaged in the research of protection system. Nuutinen et al. [7] establish the laboratory platform of DC distribution 
system, which provides an important experimental basis for the research of fault detection and protection of DC distribution system. Fault current characteristic of DC distribution system has been studied in detail [8], which lays a solid foundation for analyzing fault characteristic mechanism and exploring dynamic response characteristics. In this respect of the fault location and isolation, a handshake method is proposed in [9]. AC CBs and DC disconnectors are used to clear DC faults in this method. But the speed of protective action is slow and the nonfault bus has the problem of the short-time power interruption. In order to solve this problem, DC CBs are used to clear DC faults directly in [10]. In addition, the overall protection configuration for DC distribution system of single-end and double-end is proposed in [1113]. However, the access of DGs is not considered, and a certain gap exists with protection demands of actual projects. Overall, protection of DC distribution system is still in the beginning stage.

In this paper, a comprehensive protection scheme for DC distribution system with DG is proposed. The proposed protection scheme considers faults on both AC side and DC side and the coordination of converter protection and system protection. The rest of the paper is organized as follows. Firstly, the electromagnetic transient model for DC distribution system with DG is established by PSCAD/EMTDC. The simulation based on electromagnetic transient model is carried out to verify the accuracy of the model. Then, the fault characteristic mechanism of DC distribution system is analyzed. The protection principles and the protection scheme of DC distribution system are investigated. Finally, a series of fault simulations are completed to verify the accuracy of protection principles and scheme.

\section{Electromagnetic Transient Simulation Model for DC Distribution System with DG}

Nowadays, DC distribution system is still in the exploration stage. As a result, a good and feasible electromagnetic transient model is in great need for the research of fault analysis, fault detection, and protection of DC distribution system. In this section, the electromagnetic transient model will be introduced.

2.1. Modeling. The basic topologies of DC distribution system mainly contain radiation type, ring type, and mesh type, as shown in Figure 1. The path of power flow is certain in the radiation network, and it is also easy to control the power flow. But its reliability is low. In the ring network, the power flow between any two stations has two paths. Therefore, the reliability is high, but the control of power flow, fault detection, and protection is relatively complex. Mesh network consists of two or more rings. So the structure is more complex, the path of power flow is uncertain, and controlling the power flow is more difficult. In this research stage, the radiation system with two-wire unipolar distribution form is selected as the research object. Compared with bipolar system, unipolar system is simpler in the structure. Meanwhile, "a fire line

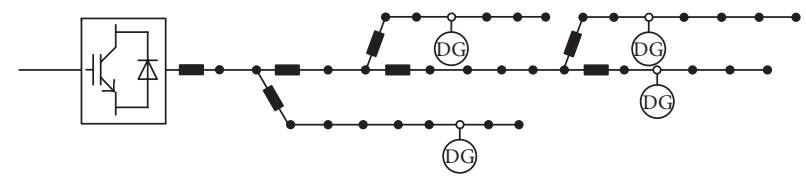

(a) Radiation type

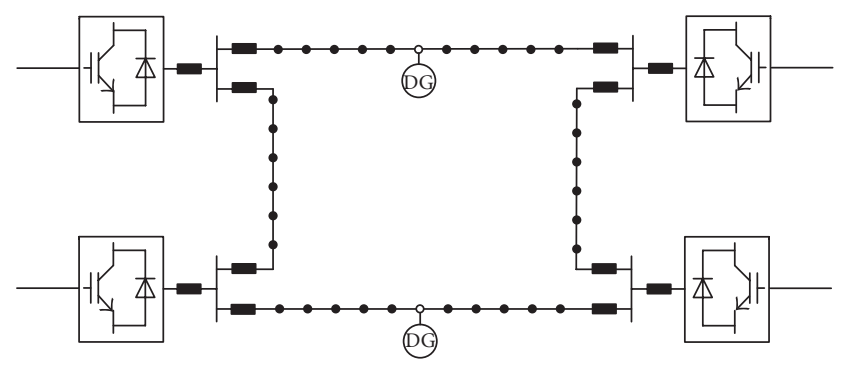

(b) Ring type

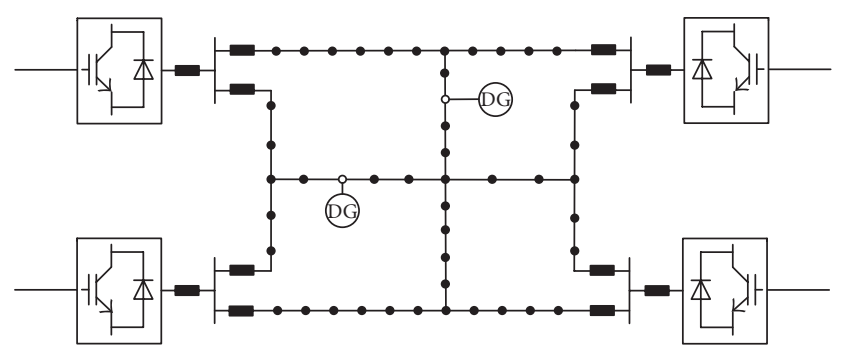

(c) Mesh type

FIgURE 1: The diagram of three kinds of the basic topologies of DC distribution system.

and an earth lead" system needs reliable grounding. The requirement is very high for grounding points and grounding equipment. Besides, "a fire line and an earth lead" system is unfavorable for underground communication cables and the personal and property safety.

According to the study of DC distribution voltage levels $[14,15]$, the paper uses $10 \mathrm{kV}$ as medium voltage (MV) DC distribution voltage and $400 \mathrm{~V}$ as low voltage (LV) DC load voltage. Besides, similar to traditional AC system, $380 \mathrm{~V}$ is still used as LV AC load voltage.

The paper uses electromagnetic transient simulation software PSCAD/EMTDC to build a radial DC distribution system model, as shown in Figure 2. $110 \mathrm{kV}$ AC system, acting as the main power supply, is connected to $10 \mathrm{kV}$ DC bus through the distribution converter station. The distribution converter station consists of $110 / 6.3 \mathrm{kV}$ distribution transformer and the rectifier. DG is linked to DC bus through DC line to supply power. The model includes three kinds of loads, that is, MV DC load, LV DC load, and LV AC load. The last two kinds of loads require conversion devices, namely, DC/DC converter and inverter.

In this paper, the rectifier and inverter are three-phase voltage source converters based on IGBTs. The rectifier uses constant DC voltage and constant reactive power strategy, and the inverter uses constant $\mathrm{AC}$ voltage strategy (viz. Vf control strategy). One buck circuit is applied as DC/DC converter, and the constant DC voltage strategy is employed 


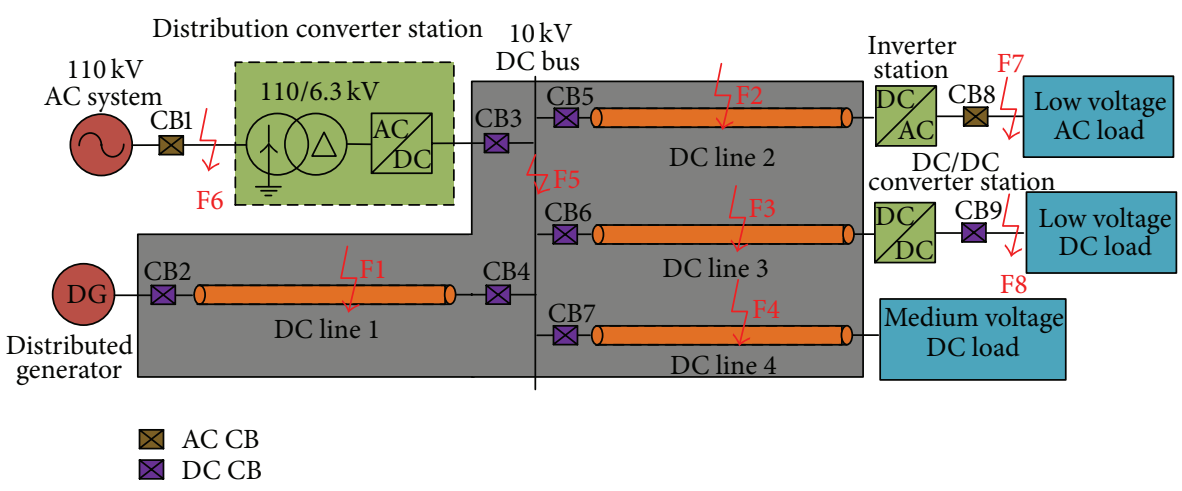

FIGURE 2: The diagram of simulation model of DC distribution system.

TABLE 1: Simulation values of electrical parameters in DC distribution system.

\begin{tabular}{|c|c|c|}
\hline \multicolumn{2}{|c|}{ Electrical parameters } & Simulation values \\
\hline \multirow{2}{*}{ The output of distribution transformer } & AC voltage $U_{T}(\mathrm{kV})$ & 6.60 \\
\hline & AC current $I_{T}(\mathrm{kA})$ & 0.95 \\
\hline \multirow{2}{*}{ MV DC voltages } & $10 \mathrm{kV}$ DC bus voltage $U_{\text {bus }}(\mathrm{kV})$ & 10.50 \\
\hline & DG output voltage $U_{\mathrm{dg}}(\mathrm{kV})$ & 10.53 \\
\hline \multirow{5}{*}{ MV DC currents } & Distribution converter station output current $I_{\mathrm{dc}}(\mathrm{kA})$ & 0.69 \\
\hline & DG output current $I_{\mathrm{dg} 1}(\mathrm{CB} 2)$ and $I_{\mathrm{dg} 2}(\mathrm{CB} 4)(\mathrm{kA})$ & 0.095 \\
\hline & $\mathrm{DC} / \mathrm{DC}$ converter station input current $I_{\text {buck }}(\mathrm{kA})$ & 0.11 \\
\hline & Inverter station input current $I_{\mathrm{inv}}(\mathrm{kA})$ & 0.162 \\
\hline & MV DC load current $I_{r}(\mathrm{kA})$ & 0.513 \\
\hline \multirow{2}{*}{ The output of DC/DC converter station } & DC voltage $U_{\text {buck }}(\mathrm{kV})$ & 0.40 \\
\hline & DC current $I_{\text {buck_o }}(\mathrm{kA})$ & 4.0 \\
\hline \multirow{2}{*}{ The output of inverter station } & AC voltage $U_{\text {inv }}(\mathrm{kV})$ & 0.38 \\
\hline & AC current $I_{\text {inv_o }}(\mathrm{kA})$ & 2.57 \\
\hline
\end{tabular}

in this system. As a typical DG, photovoltaic (PV) is adopted in the model according to the literature [16]. The cable is used as DC line, and the frequency dependent (phase) model of cable is chosen.

2.2. Validation of the Simulation Model. The simulation on the electromagnetic transient of DC distribution system is carried out to verify the accuracy of the model presented in the paper. The transient characteristic on DC and AC side from startup state to normal operation state is shown in Figure 3. It can be concluded that the system has a good transient step response within the prescribed rise time of $1 \mathrm{~s}$.

The electrical parameters of the system at steady state are listed in Table 1. According to Figure 3 and Table 1, it is demonstrated that the output AC voltage and current of distribution transformer are in phase. So the unity power factor control of the rectifier is achieved. In MV DC system, DC bus voltage is maintained at $10.5 \mathrm{kV}$, which meets the requirement for voltage at the beginning of distribution lines. The output currents of distribution converter station and DG are maintained at $0.69 \mathrm{kA}$ and $0.095 \mathrm{kA}$. The input currents of $\mathrm{DC} / \mathrm{DC}$ converter station, inverter station, and MV DC load are at $0.11 \mathrm{kA}, 0.162 \mathrm{kA}$, and $0.513 \mathrm{kA}$, respectively. Therefore, the load power is consistent with the transmission power. The output voltages of DC/DC converter station and inverter station are maintained at $400 \mathrm{~V}$ and $380 \mathrm{~V}$, which satisfy the desired values of load voltages. Meanwhile, the harmonic contents of all electrical parameters are within the acceptable range.

In Figure 3 and Table 1, both the step response and the steady-state performance are shown to verify the accuracy of the model.

\section{Protection System}

DC distribution protection system is divided into three protection levels, namely, component level, device level, and system level. The researches of short circuit protection of component and device, such as the IGBT and the converter, have been addressed in many publications [17-20]. Hence, the protection presented in this paper is primarily focused on system level. The protection configuration is concentrated on the medium voltage DC (MVDC) area in Figure 2. Moreover, the protection coordination between system level and device level is also taken into account. 

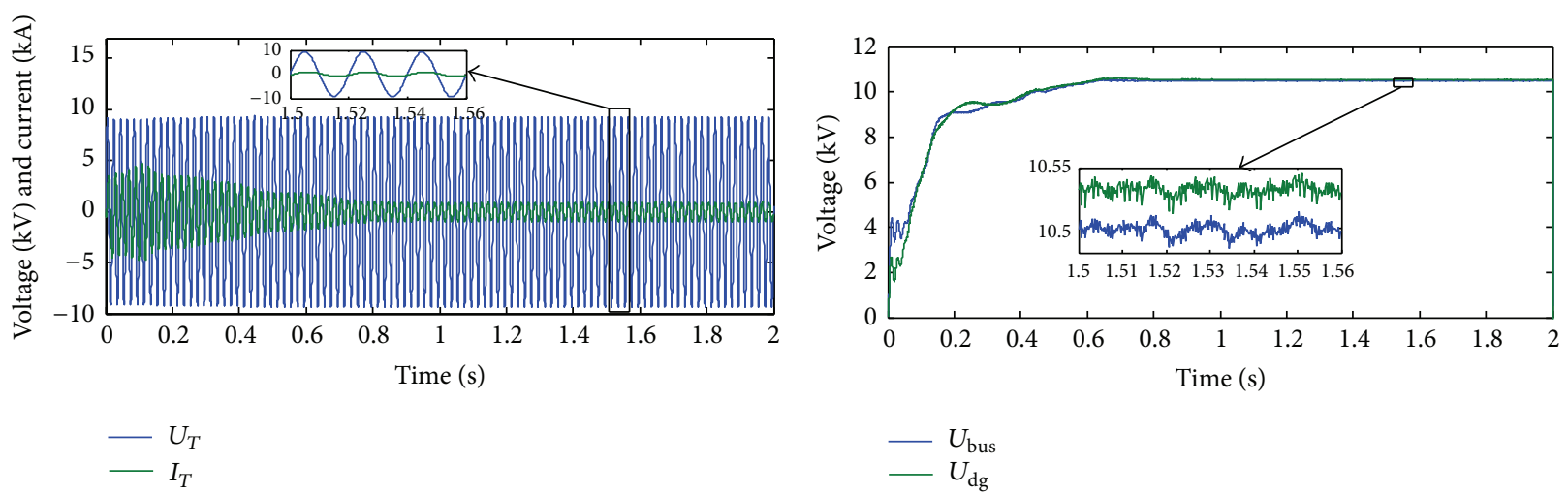

(a) Output A-phase voltage and current of transformer

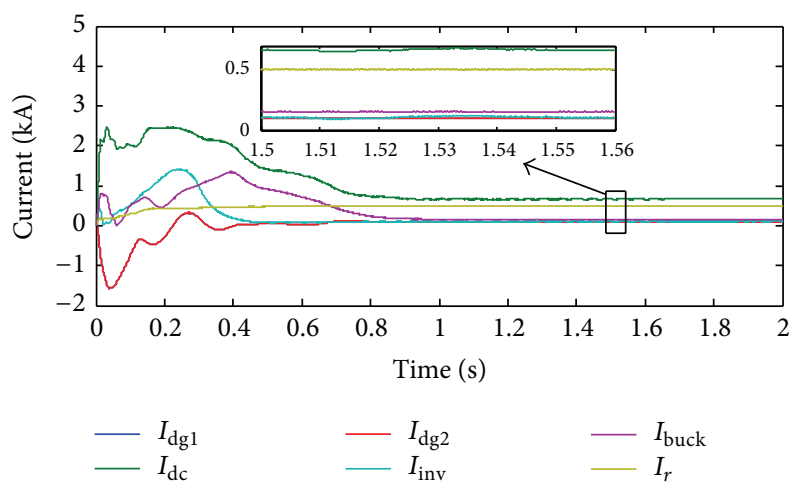

(c) MV DC currents

(b) MV DC voltages

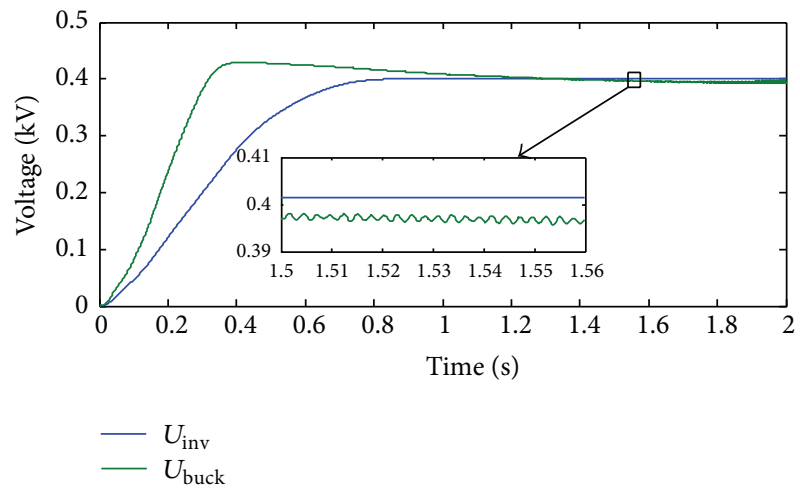

(d) The RMS voltages of AC load and DC load

Figure 3: The step response waveforms.

3.1. Fault Characteristic Mechanism Analysis. The fault characteristic is the basic of protection. Hence, the fault characteristic mechanism of DC distribution system needs to be analyzed. In this section, the DC short-circuit fault characteristic of the rectifier and DG will be introduced emphatically.

Firstly, the fault characteristic mechanism of the rectifier is analyzed. Once a short-circuit fault occurs in the DC side of the rectifier, IGBTs will be blocked by the self-protection. So the full-controlled rectifier becomes the uncontrolled rectifier. Then, the rectifier goes through the four transient stages as shown in Figure 4.

Stage 1. As DC voltage is always greater than the instantaneous value of AC line voltage, all the diodes are turned off, and the capacitor discharges via the short circuit. At this stage, the fault voltage and current can be solved by using the second-order circuit. With the continuing decline of the capacitor voltage, Stage 2 starts when DC voltage is less than the maximum instantaneous value of AC line voltage.

Stage 2. In this stage, the capacitor discharges with the diodes turning-on alternatively. The energy of fault circuit mainly comes from the capacitor. While the capacitor is discharging continuously, the rectifier will enter Stage 3 if the capacitor voltage is reduced to zero at a certain time; otherwise, it will step into Stage 4 directly.
Stage 3. The capacitor is shorted by the freewheeling diodes. The equivalent inductance discharges via the diodes. In this stage, the fault voltage and current can be solved by using the first-order circuit. With the continuing decline of the fault current, these diodes cannot be turning on once the instantaneous value of AC phase current is greater than that of freewheeling current. Then the rectifier begins to enter Stage 4 .

Stage 4. The fault circuit is equivalent to the $R L C$ load for the rectifier. The energy of the fault circuit mainly comes from AC system.

According to the related formulas [21], the theoretical calculation and fault simulation confirm that the analysis of four-stage fault mechanism is correct. Figure 5 shows the fault characteristic under a particular situation of simulation system parameters and initial values. Therefore, the overall fault characteristic of the rectifier is that DC voltage drops rapidly to the steady-state value, while DC current increases rapidly and then decreases to the steady-state value.

Then, the fault characteristic mechanism of the DG is briefly introduced. As described in the second chapter, PV is used in the model. The equivalent circuit model and gridconnected circuit of PV are shown in Figure 6. Similar to the rectifier, DG goes through two main stages during the shortcircuit fault: (1) capacitor discharge stage and (2) DG-side 


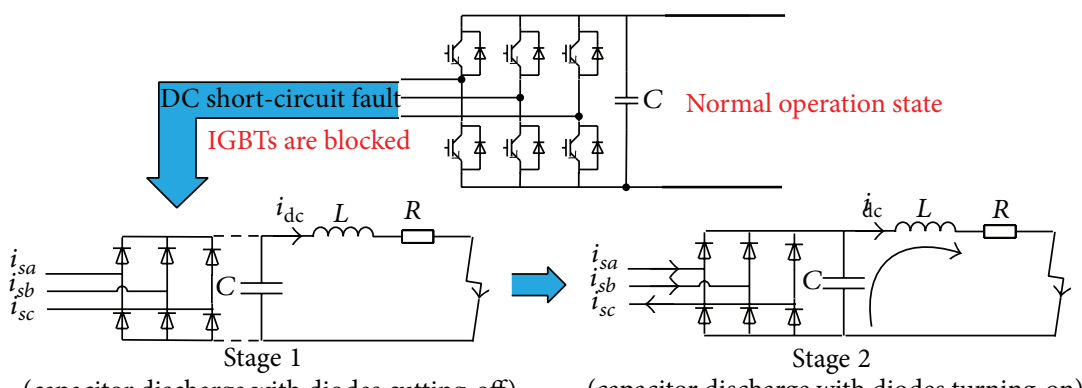

(capacitor discharge with diodes cutting-off)

(capacitor discharge with diodes turning-on)

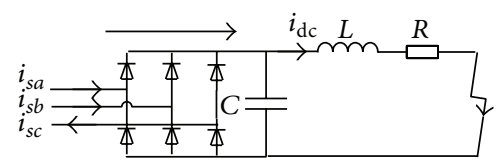

Stage 4

(grid-side current feeding)

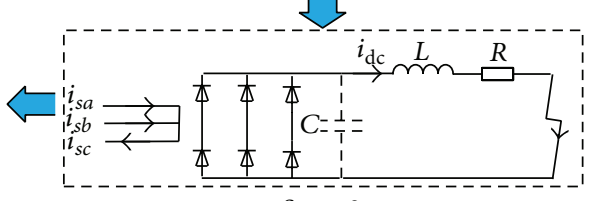

Stage 3

(inductance discharge with diode freewheel)

FIGURE 4: The four transient stages for the rectifier during DC short-circuit fault.

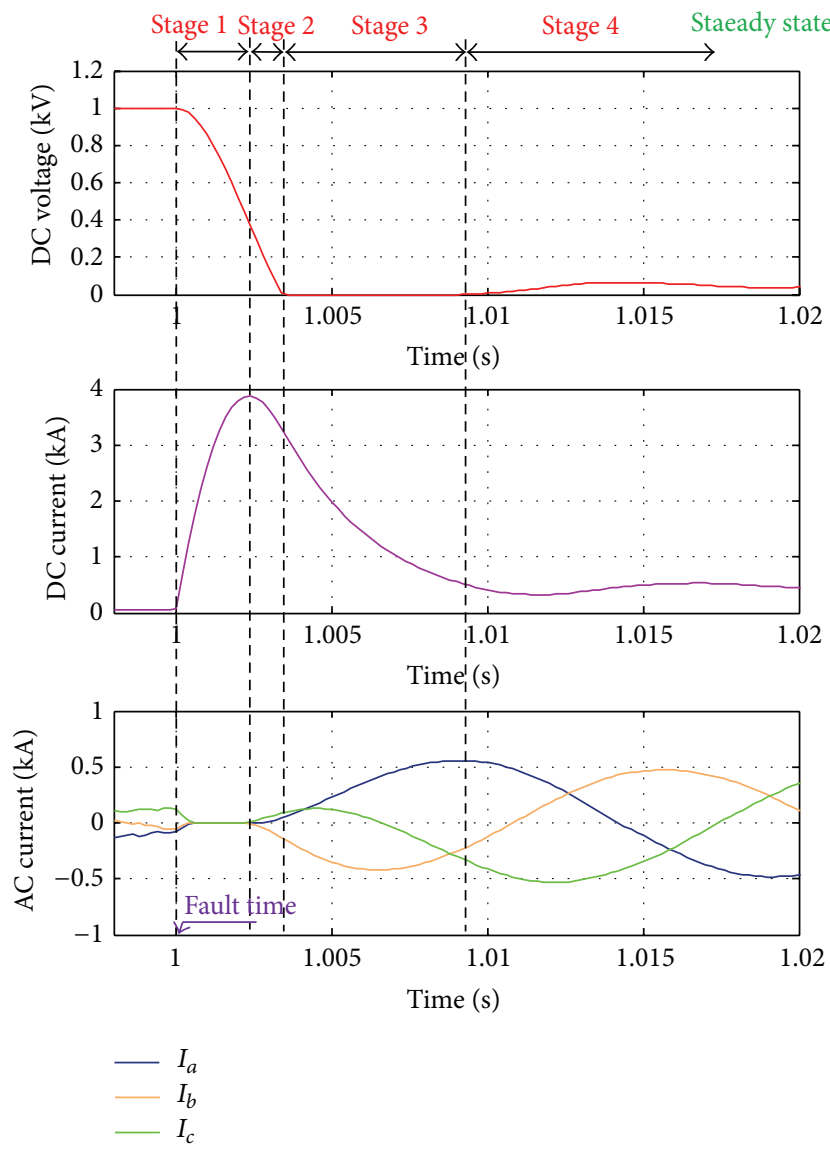

FIGURE 5: The fault characteristic diagram of the rectifier during DC short-circuit fault.

current feeding stage. The overall fault characteristic is similar to that of the rectifier.

According to the fault mechanism analysis mentioned above, the short-circuit fault characteristic of DC distribution

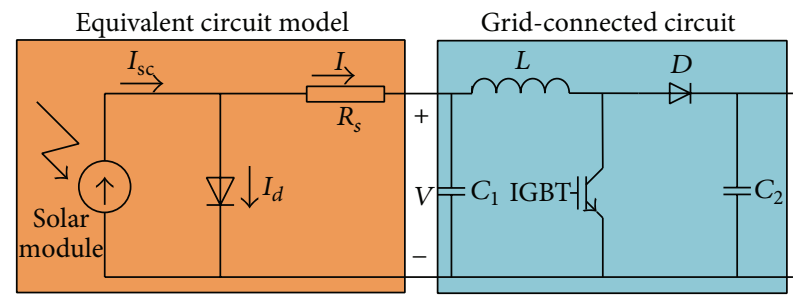

FIGURE 6: The equivalent circuit model and grid-connected circuit of PV.

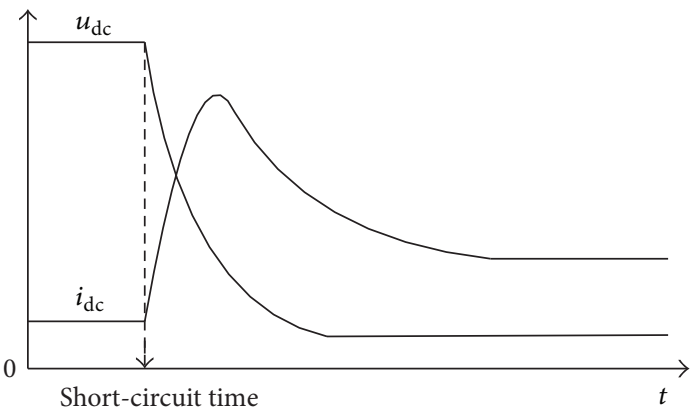

FIGURE 7: The schematic waveforms of DC voltage and current during faults.

system is obtained. The schematic waveforms of DC voltage and current during faults are shown in Figure 7.

3.2. Protection Principles. According to the fault characteristic mechanism analysis and the schematic waveforms of DC voltage and current during faults, the following protection principles are proposed in the paper.

(1) Protection Starting Component-Voltage Mutation Principle. Protection starting component is the primary guarantee for judging and removing faults rapidly, sensitively, and 
reliably. Based on the fault transient characteristic that DC voltage drops rapidly, the voltage mutation starting component is put forward. The principle is used as the starting component of protection for both DC bus and DC line. The basic criterion of starting component is expressed as

$$
\Delta u>\Delta u_{\text {set }}
$$

where $\Delta u$ is DC voltage mutation and $\Delta u_{\text {set }}$ is the protection startup setting value. The setting principle is to ensure that the setting value is always greater than the maximum fluctuation value of DC voltage. The maximum fluctuation value, margin multiple, and sampling frequency should be considered when $\Delta u_{\text {set }}$ is set.

(2) Fault of DC Bus-Differential Current Protection Principle. To meet the requirement of rapidity and selectivity, the differential current protection principle based on Kirchhoff's current law is used as the main protection of DC bus. In this paper, the positive direction of the current flowing through $\mathrm{CB}$ is assumed from DC bus to line. The differential current is defined as the opposite number of the sum of currents of all CBs connected to the DC bus. If the DC bus is considered as a node, the differential current is zero under normal or external fault states. However, when a short-circuit fault occurs in DC bus, the differential current is equal to the fault current. Hence, the basic criterion for the differential current protection is expressed as

$$
I_{d}>I_{\text {bus_set }},
$$

where $I_{d}$ is the differential current and $I_{\text {bus_set }}$ is the setting value of the differential current. The setting principle is to ensure that the setting value is always greater than the sum of the maximum measurement error value of every current transformer under external fault states. Hence, the maximum measurement error of current transformer and margin multiple should be considered when $I_{\text {bus_set }}$ is set.

Differential current protection has high selectivity almost without delay. Generally, the fault current of DC bus is much larger than the setting value, so differential current protection also has high sensitivity.

(3) Fault of DC Line-Two-Section Current Protection Principle. When a fault occurs in lines, DC bus voltage declines rapidly and the capacitors connected with the bus discharge quickly to the fault point, leading to the rapid rise of the fault-line current. Based on the transient characteristic, twosection current protection principle is proposed as primary and backup protection for DC lines. The protection principle contains instantaneous current quick-break protection and time-limit current quick-break protection.

Instantaneous current quick-break protection means that once the fault current exceeds the setting value, the protection should act immediately. It is the primary protection. Hence, the basic criterion for instantaneous current quick-break protection is expressed as

$$
I_{i}>I_{i_{-} \text {set_1 }}
$$

where $I_{i}$ is the current flowing through $\mathrm{CB} i$ and $I_{i_{\text {sset_1 }}}$ is the instantaneous current setting value of $\mathrm{CB} i$. The setting principle is to ensure that the trip command is given during the rising period of short-circuit current and the protection range is the entire line. The value of the capacitors, the line impedance parameters, and margin multiple should be considered when $I_{i_{\text {_set_l }}}$ is set.

Time-limit current quick-break protection is the current protection with a certain delay. It is the backup protection. The basic criterion for time-limit current quick-break protection is expressed as

$$
\begin{aligned}
& I_{i}>I_{i_{\text {_set_2 }}} \\
& t_{i}>t_{i_{\text {_set }}},
\end{aligned}
$$

where $I_{i_{-} \text {set_2 }}$ is the time-limit current setting value of $\mathrm{CB} i$ and $t_{i_{\text {set }}}$ is the protection delay setting value of $\mathrm{CB} i$. The setting principle is to ensure that the protection can still act correctly, when distribution system reaches steady state after faults. Therefore, the protection delay setting value is close to the duration of the fault transient process, and the timelimit current setting value is always less than the steady-state short-circuit current. The value of the capacitors, the line impedance parameters, and margin multiple should be also considered when $I_{i_{\text {_set_2}}}$ and $t_{i_{\text {_set }}}$ are set.

3.3. Protection Scheme. A protection scheme is proposed based on the local information, which uses voltage mutation principle as protection starting component, differential current protection principle as DC bus protection, and twosection current protection principle as DC line protection. When two-section current protection principle is applied in the protection scheme, attention should be paid to smoothing away the following two problems.

(1) There are two power supplies for CB3 and CB4, so the problem about reverse current should be considered. When a fault occurs in DC line 1, the current flowing through CB4 reverses. Similarly, when a fault occurs on AC side of the rectifier, the current flowing through CB3 reverses. Hence, the paper proposes reverse current protection principle. When the current flowing through $\mathrm{CB} 3$ or CB4 reverses, the protection system should trip CB3 or CB4 immediately. The basic criterion for reverse current protection is expressed as

$$
I_{i}>\varepsilon_{i}
$$

where $\varepsilon_{i}$ is a small positive value on behalf of reverse current margin. The current flowing through CB3 or CB4 is negative under normal situation.

(2) When a fault occurs in line 2 to 4 , the value of fault current provided by DG may exceed the instantaneous current setting value of CB2. To meet the requirement of protection selectivity, the instantaneous current setting value should be close to the maximum transient current in the case that the fault happens at the remote terminal of DC line 1. It must be ensured that fault current through CB2 cannot exceed the instantaneous current setting value before the removal time of the downstream fault. Hence, the protection 
TABLE 2: The setting values of parameters (sampling frequency of protection device: $5 \mathrm{kHz}$ ).

\begin{tabular}{|c|c|c|c|}
\hline \multirow{2}{*}{$\begin{array}{l}\text { Protection types } \\
\text { Start component }\end{array}$} & \multicolumn{2}{|l|}{ Parameters } & \multirow{2}{*}{$\begin{array}{c}\text { Setting values } \\
0.1\end{array}$} \\
\hline & Protection startup setting value & $\Delta u_{\text {set }}(\mathrm{kV})$ & \\
\hline DC bus protection & Differential current setting value & $I_{\text {bus_set }}(\mathrm{kA})$ & 0.5 \\
\hline \multicolumn{4}{|l|}{ DC line protection } \\
\hline \multirow{4}{*}{ Line 1 (CB2, CB4) } & Instantaneous current setting value & $I_{2 \text { _set_l }}(\mathrm{kA})$ & 2.5 \\
\hline & Time-limit current setting value & $I_{2 \text { _set_2 }}(\mathrm{kA})$ & 0.6 \\
\hline & Delay setting value & $t_{2 \text { set }}(\mathrm{s})$ & 0.1 \\
\hline & Reverse current margin & $\varepsilon_{4}(\mathrm{kA})$ & 0.05 \\
\hline \multirow{3}{*}{ Line 2 (CB5) } & Instantaneous current setting value & $I_{5 \text { set_l }}(\mathrm{kA})$ & 1.3 \\
\hline & Time-limit current setting value & $I_{5 \text { _set_2 }}(\mathrm{kA})$ & 0.7 \\
\hline & Delay setting value & $t_{5 \_ \text {set }}(\mathrm{s})$ & 0.1 \\
\hline \multirow{3}{*}{ Line 3 (CB6) } & Instantaneous current setting value & $I_{6 \_ \text {set_l } 1}(\mathrm{kA})$ & 1.2 \\
\hline & Time-limit current setting value & $I_{6 \_ \text {set_2 }}(\mathrm{kA})$ & 0.7 \\
\hline & Delay setting value & $t_{6 \_s e t}(s)$ & 0.1 \\
\hline \multirow{3}{*}{ Line 4 (CB7) } & Instantaneous current setting value & $I_{7 \text { _set_l } 1}(\mathrm{kA})$ & 1.4 \\
\hline & Time-limit current setting value & $I_{7 \text { _set_2 }}(\mathrm{kA})$ & 0.7 \\
\hline & Delay setting value & $t_{7 \_ \text {set }}(\mathrm{s})$ & 0.1 \\
\hline The outlet of rectifier (CB3) & Reverse current margin & $\varepsilon_{3}(\mathrm{kA})$ & 0.05 \\
\hline
\end{tabular}

scheme sacrifices the rapidity when setting instantaneous current for CB2.

There are two relay locations in the MVDC area of Figure 2, namely, DC bus (CB3 to CB7) and the outlet of DG (CB2). The protection types, the setting principles of parameters, and the setting values mentioned above are listed in Table 2 . The protection flowcharts are shown in Figure 8.

\section{Verification of Protection System}

In this paper, two sets of fault simulation experiments are conducted to verify whether the protection scheme meets the protection requirements or not. The first set of experiments includes the short-circuit fault on line 1 to 4 (F1 to F4) and DC bus fault (F5) as shown in Figure 2. These experiments are used to verify rapidity, sensitivity, and reliability of protection system. The other set of experiments includes three-phase short-circuit fault in AC system (F6), three-phase shortcircuit fault in LV AC load (F7), and short-circuit fault in LV DC load (F8). These experiments are used to test selectivity and reliability of protection system. The short-circuit times of all faults are uniformly set at $2 \mathrm{~s}$ in the experiments. The protection principles and protection scheme are achieved by programming on the software MATLAB.

4.1. Faults in MVDC Area (F1 to F5). As shown in Table 3, once faults (F1 to F5) occur, the rectifier can be reliably blocked within $3 \mathrm{~ms}$ by itself over-current protection. At the same time DC protection system can rapidly and reliably trip appropriate DC CB to remove the fault from the system. Because of limitations of space, only faults F1, F3, and F5 are analyzed in the paper. For line faults, the fault points are located at the middle of the lines. Considering the rapidity of DC CB, the switch-off time of CB is set as $10 \mathrm{~ms}$. So, the action time of $\mathrm{CB}$ is equal to the time receiving trip instruction plus the switch-off time. Figures 9, 10 and 11 are the transient response waveforms of fault F3, F5 and F1.

DC voltage rapidly declines when fault F3 occurs, which leads the fast startup of mutation component. IGBTs of the rectifier are blocked by the self-protection. The capacitors of the rectifier, DG, and inverter discharge immediately and contribute to the fault point together with the fault current $I_{\text {buck }}$. Especially, the discharge current of the inverter reversely flows through CB5. At $1 \mathrm{~ms}$ after the fault, $I_{\text {buck }}$ is up to the instantaneous current setting value of CB6. Then the protection system sends a trip command to CB6 immediately and CB6 is tripped after $10 \mathrm{~ms}$, while $I_{\mathrm{dg} 1}$ (the current flowing through CB2) is up to the instantaneous current setting value of CB2 at $62 \mathrm{~ms}$ after the fault with the inaction of CB6. Hence, maloperation does not occur in CB2.

When fault F5 occurs, DC voltage mutation component starts immediately. Simultaneously, the value of differential current has already exceeded the setting value. The protection system sends trip commands to CB3 and CB4 at $0.8 \mathrm{~ms}$ after the fault. $\mathrm{CB} 3$ and $\mathrm{CB} 4$ are tripped after $10 \mathrm{~ms}$. Besides the rectifier and DG, the capacitors of DC/DC converter and the inverter discharge and contribute the capacitive current to the short-circuit point. In addition, $I_{\mathrm{dg} 1}$ is up to the setting value at $23.6 \mathrm{~ms}$ after the fault. Therefore, maloperation does not occur in CB2 as well.

As similar with faults $\mathrm{F} 3$ and F5, $I_{\mathrm{dg} 1}$ is up to the instantaneous current setting value for CB2 at $12 \mathrm{~ms}$ after fault F1. Then protection system sends a trip command to CB2. At $1 \mathrm{~ms}$ after the fault, a trip command is sent to CB4 due to the sensitive reverse current protection. So CB4 and CB2 are tripped successively at $10 \mathrm{~ms}$ after the trip commands are given.

4.2. Faults in Non-MVDC Area (F6 to F8). Results show that reverse current protection acts for CB3 and prevents DC system from supplying power to the fault point in 


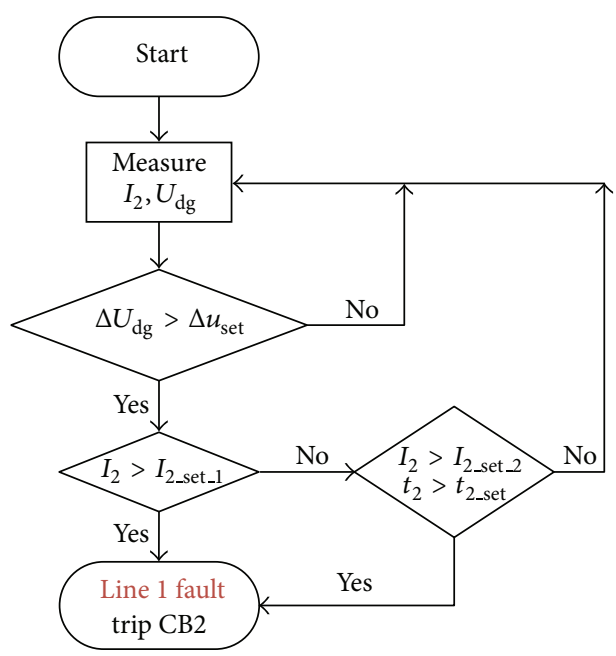

(a) Relay location of the outlet of DG

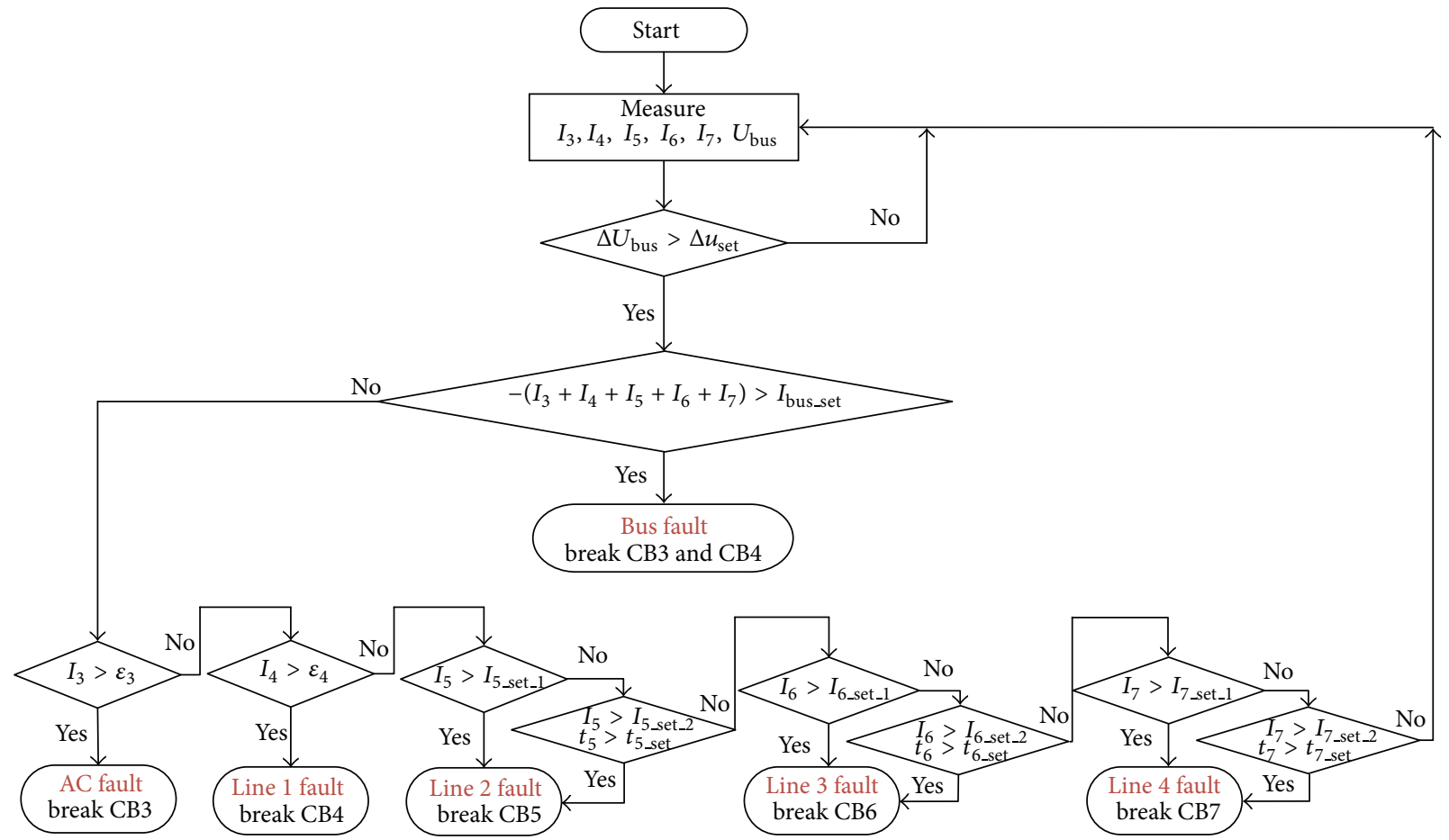

(b) Relay location of DC bus

FIgURE 8: Flow charts of relay locations.

the case of fault F6. While in the cases of faults F7 and F8, all of the breakers (CB2 to CB6) will not act. Considering DC protection system and the self-protection of the converters, a detailed analysis of fault F6 to F8 is conducted. Figures 12, 13 and 14 are the transient response waveforms of fault F6, F7 and F8.

When fault F6 occurs, the capacitors of the DG, DC/DC converter, and inverter discharge with the rapid reduction of AC voltage of the rectifier. Thus $I_{\mathrm{dg}}$ increases rapidly, while $I_{\text {inv }}$ and $I_{\text {buck }}$ increase reversely to inject the rectifier. At $8.4 \mathrm{~ms}$ after the fault, $I_{\mathrm{dc}}$ flowing through CB3 is up to the reverse current setting value. Therefore, the protection system sends a trip command to CB3, and CB3 is tripped after $10 \mathrm{~ms}$.

When fault F7 occurs, there is a slight fluctuation for DC voltage, while DC current of the inverter increases rapidly for a short time, which is provided in large part by the rectifier and in small part by DG. However, the starting component has not been operated during the whole transient period of the fault. Therefore, maloperation does not occur for the protection system.

When it comes to fault F8, it is essential to consider the overcurrent protection of DC/DC converter. When fault 
TABLE 3: The action situation of each CB during F1-F5.

\begin{tabular}{|c|c|c|c|c|c|c|c|c|}
\hline \multirow{2}{*}{ Fault type } & \multirow{2}{*}{ Percentage of fault location } & \multirow{2}{*}{ Rectifier blocked time (s) } & \multicolumn{6}{|c|}{ The action of breakers (time for receiving trip instruction) } \\
\hline & & & $\mathrm{CB} 2$ & CB3 & CB4 & CB5 & CB6 & CB7 \\
\hline \multirow{3}{*}{$\mathrm{F} 1$} & $10 \%$ & 2.0022 & $+(2.0082)$ & \# & $+(2.0012)$ & \# & \# & \# \\
\hline & $50 \%$ & 2.0016 & $+(2.0120)$ & \# & $+(2.0010)$ & \# & \# & \# \\
\hline & $100 \%$ & 2.0010 & $+(2.0200)$ & \# & $+(2.0008)$ & \# & \# & \# \\
\hline \multirow{3}{*}{$\mathrm{F} 2$} & $10 \%$ & 2.0010 & $\#$ & $\#$ & $\#$ & $+(2.0010)$ & $\#$ & $\#$ \\
\hline & $50 \%$ & 2.0016 & $\#$ & $\#$ & $\#$ & $+(2.0010)$ & $\#$ & $\#$ \\
\hline & $100 \%$ & 2.0024 & $\#$ & $\#$ & $\#$ & $+(2.0018)$ & $\#$ & $\#$ \\
\hline \multirow{3}{*}{ F3 } & $10 \%$ & 2.0010 & \# & $\#$ & \# & \# & $+(2.0010)$ & $\#$ \\
\hline & $50 \%$ & 2.0014 & $\#$ & $\#$ & \# & \# & $+(2.0010)$ & $\#$ \\
\hline & $100 \%$ & 2.0024 & $\#$ & $\#$ & \# & \# & $+(2.0010)$ & $\#$ \\
\hline \multirow{3}{*}{$\mathrm{F} 4$} & $10 \%$ & 2.0010 & $\#$ & $\#$ & $\#$ & $\#$ & \# & $+(2.0010)$ \\
\hline & $50 \%$ & 2.0016 & $\#$ & $\#$ & $\#$ & $\#$ & $\#$ & $+(2.0010)$ \\
\hline & $100 \%$ & 2.0024 & $\#$ & $\#$ & $\#$ & $\#$ & $\#$ & $+(2.0014)$ \\
\hline F5 & - & 2.0010 & $\#$ & $+(2.0008)$ & $+(2.0008)$ & $\#$ & $\#$ & $\#$ \\
\hline
\end{tabular}

Note: results noted "+" are on behalf of the action of $\mathrm{CB} i$ and results noted "\#" are on behalf of the inaction of $\mathrm{CB} i$.

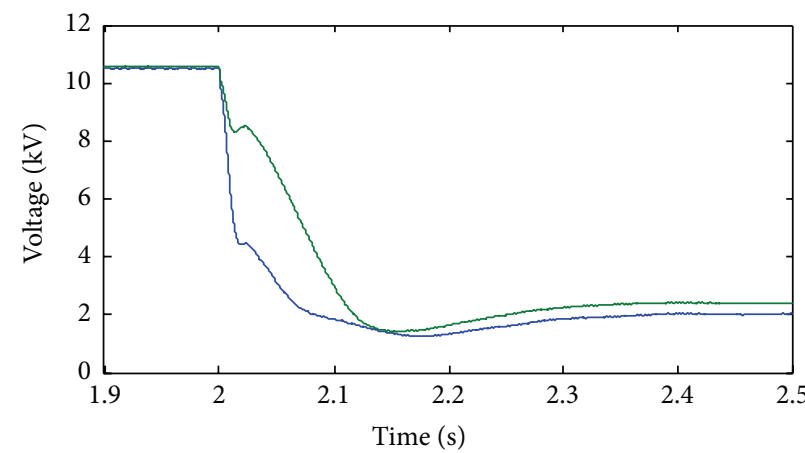

$$
\begin{aligned}
& U_{\mathrm{bus}} \\
& -U_{\mathrm{dg}}
\end{aligned}
$$

(a) MV DC voltages

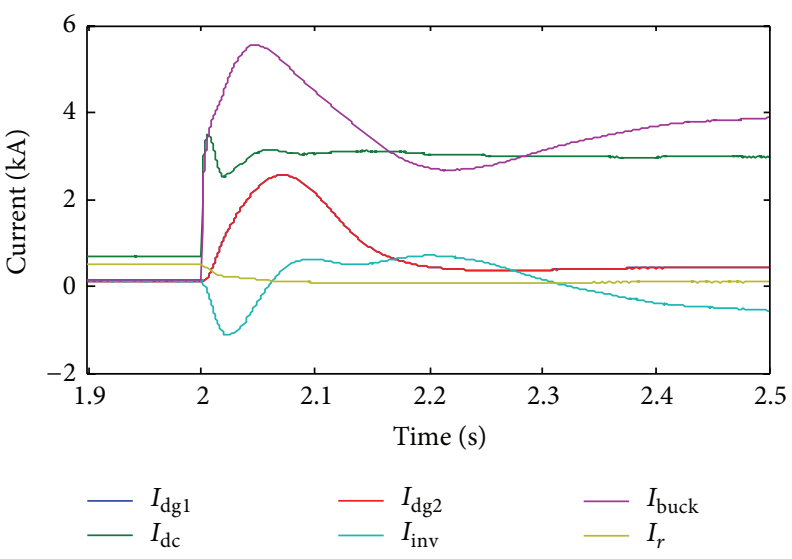

(b) MV DC currents

FIGURE 9: Transient response waveforms of fault F3.

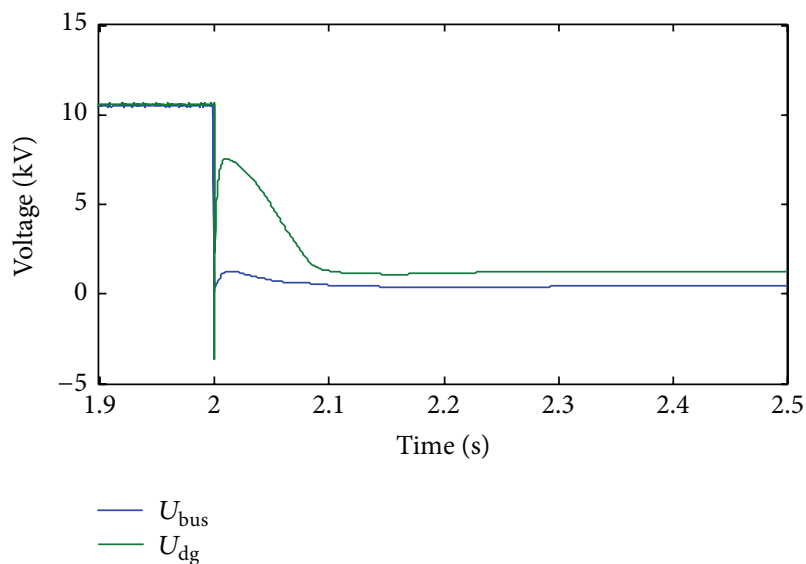

(a) MV DC voltages

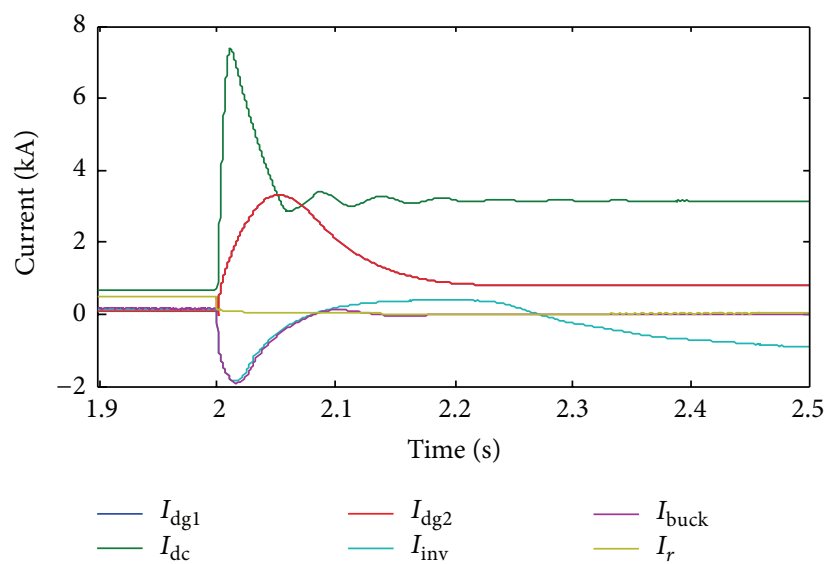

(b) MV DC currents

FIGURE 10: Transient response waveforms of fault F5. 


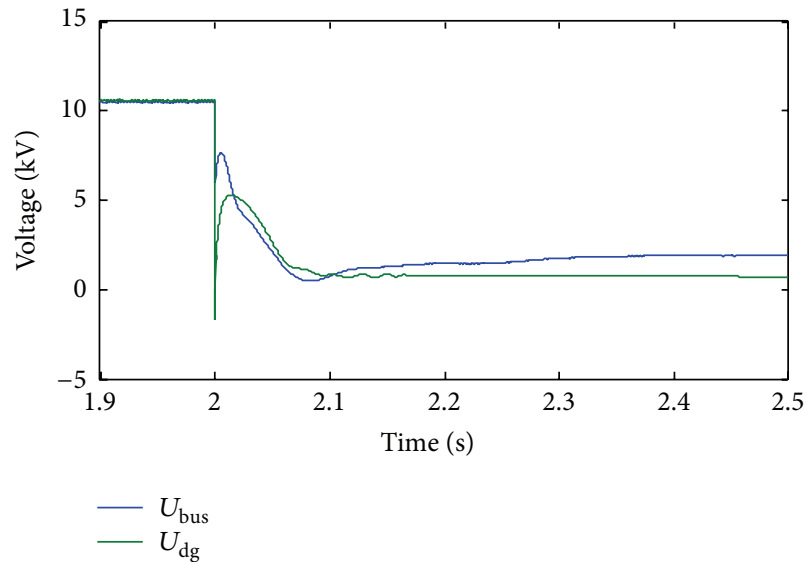

(a) MV DC voltages

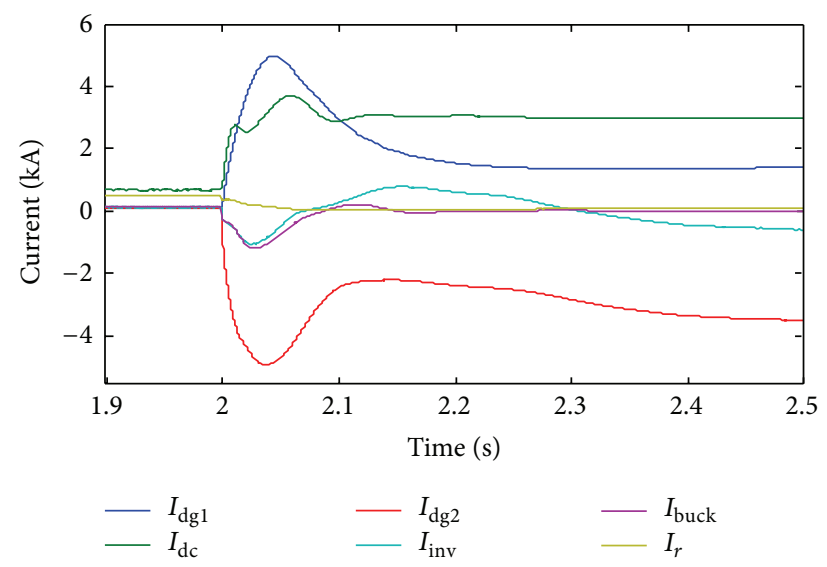

(b) MV DC currents

FIgURE 11: Transient response waveforms of fault F1.

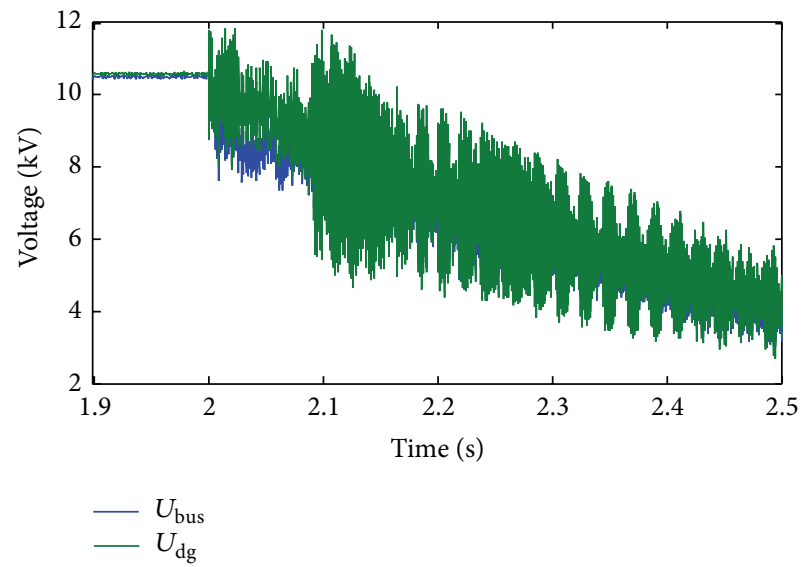

(a) MV DC voltages

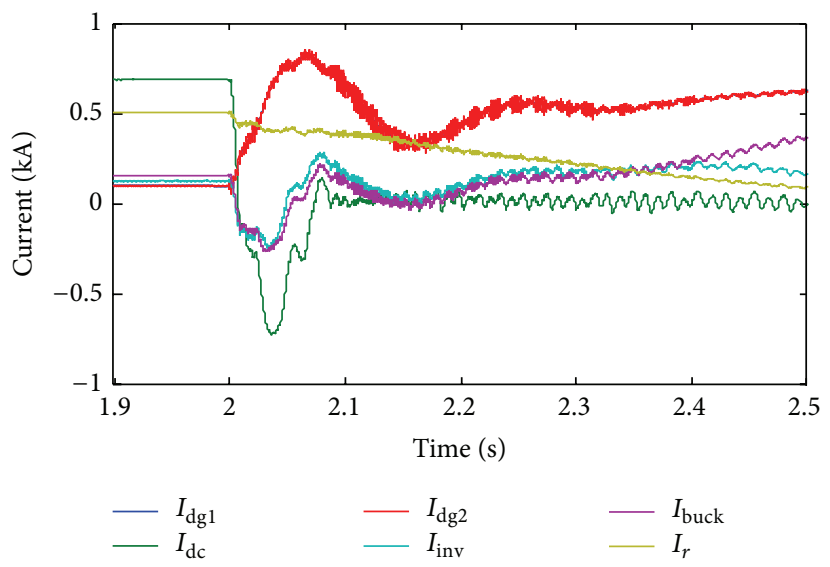

(b) MV DC currents

FIGURE 12: Transient response waveforms of fault F6.

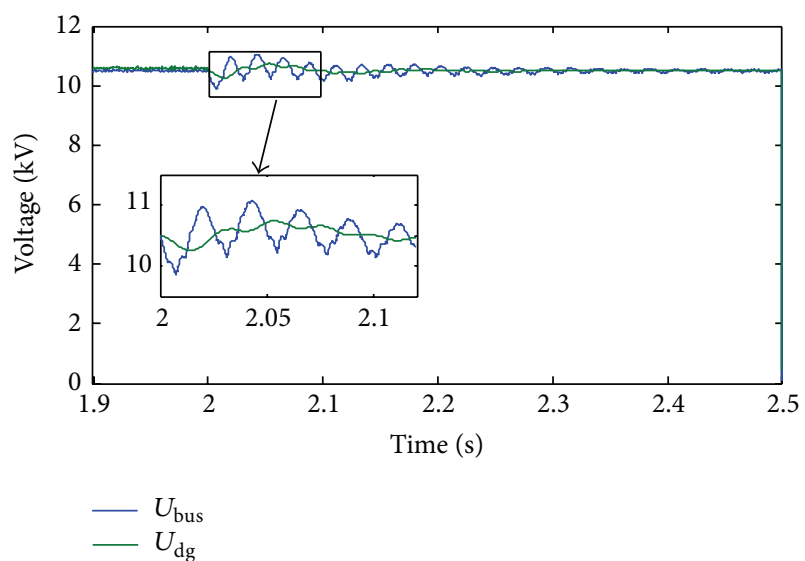

(a) MV DC voltages

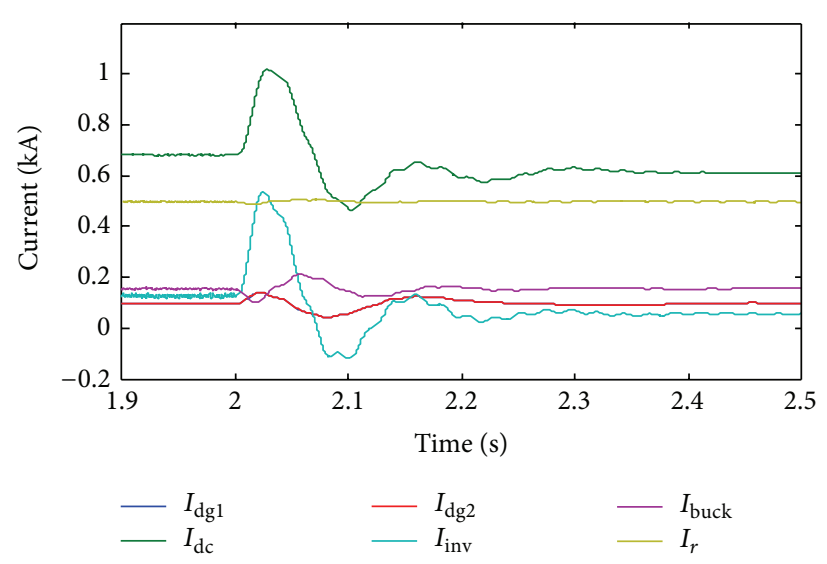

(b) MV DC currents

FIGURE 13: Transient response waveforms of fault F7. 


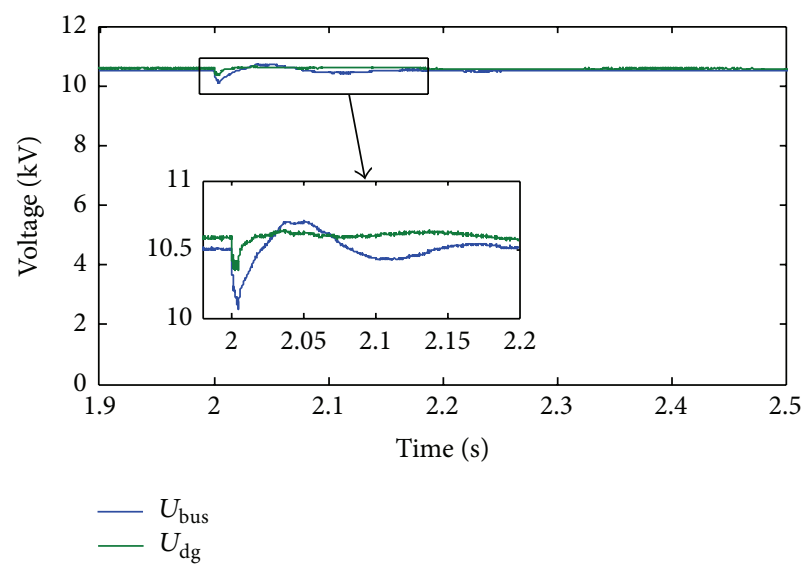

(a) MV DC voltages

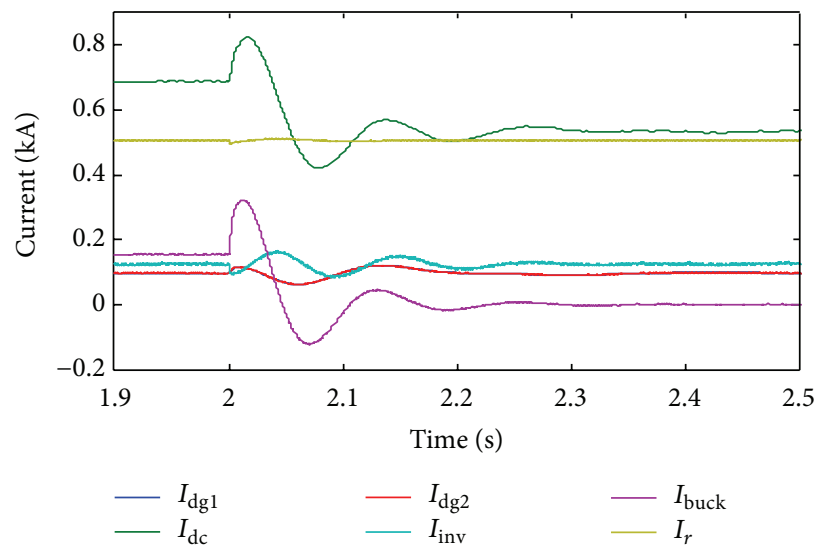

(b) MV DC currents

Figure 14: Transient response waveforms of fault F8.

F8 occurs, MV DC voltages rapidly decline, while $I_{\text {inv }}$ flowing through CB6 increases rapidly. Meanwhile, the current flowing through IGBT in DC/DC converter has a rapid rise. Considering the self-protection of DC/DC converter, the IGBT is blocked at $5 \mathrm{~ms}$ after the fault. What is more, the IGBT can be regarded as an ideal DC CB to isolate the fault influence on MV DC system. Thus, maloperation does not occur for the protection system by the self-protection of DCDC converter. Of course, it is still necessary to equip with DC CB in LV DC system to isolate the fault.

From what mentioned above, the paper draws the conclusions as follows.

(1) The protection scheme proposed in the paper is able to meet the protection demands of selectivity, rapidity, sensitivity, and reliability. Once DC short-circuit fault occurs in the MV DC area, voltage mutation component acts immediately. For faults F2-F5, the protection system can send out the trip command within $2 \mathrm{~ms}$. For fault F1, the trip command can be sent out within $20 \mathrm{~ms}$ longer than the former due to the demand of selectivity. For AC fault F6, protection system can send out the trip command within $8 \mathrm{~ms}$ and prevent DC system from supplying power to the fault point at AC side. Protection system can be reliably blocked without maloperation for LV load faults F7-F8.

(2) Once DC short-circuit fault occurs in the MV DC area, the capacitors of converters discharge immediately. Therefore, the capacitive currents are injected into the DC system reversely for DC/DC converter and the inverter. It aggravates damage to the system and improves the requirement for interrupting capacity of DC CB. To solve the problem completely, the paper proposes to employ an interface diode on the DC side of DC/DC converter and the inverter.

(3) Different from AC system, DC distribution system uses kinds of converters, such as rectifier, inverter, and DC/DC converter. The converters need to be equipped with protection because of the poor capability of bearing high voltage and large current. As a result, when configuring protection for DC distribution system, it is necessary to consider the coordination between system protection and self-protection of converters.

\section{Conclusion}

In this paper, a comprehensive protection scheme of DC distribution system with DG is proposed. First, the electromagnetic transient model of DC distribution system with DG is presented. This model is verified with both steadystate and transient performance. Then the fault characteristic mechanism is analyzed. The overall fault characteristic is that DC voltage drops rapidly to the steady-state value, while DC current increases rapidly and then decreases to the steady-state value. Based on the fault characteristic, the protection principles are investigated. And a protection scheme is proposed, which utilizes DC circuit breakers and local information. The protection scheme with different faults is investigated (including five different short-circuit faults on MV DC side, a fault on AC power side, and two faults on LV loads). The results verify that the proposed protection scheme is effective for protection of DC distribution system with DG, which has good reference value to guide future DC distribution system protection configuration. Finally, the coordination of the converter protection and the system protection is also considered, as the converters are widely used in DC distribution system. To solve the problem of reversal injection of capacitive current, the paper proposes to employ an interface diode on the DC side of DC/DC converter and inverter.

\section{Conflict of Interests}

The authors declare that there is no conflict of interests regarding the publication of this paper.

\section{Acknowledgments}

This work was supported in part by the National Natural Science Foundation of China (no. 51207103), in part by 
the State Grid Corporation of China (no. pd71-12-004), in part by the Tianjin Municipal Natural Science Foundation (no. 14JCYBJC21000), in part by the Innovation Foundation of Tianjin University (no. 2014XRG-0118), and in part by Specialized Research Fund for the Doctoral Program of Higher Education for New Teacher (no. 20120032120085).

\section{References}

[1] Y. Yu, "Intelligent distribution network in the new situation," Power System and Clean Energy, vol. 25, no. 7, pp. 1-3, 2009.

[2] M. Starke, L. M. Tolbert, and B. Ozpineci, "AC versus DC distribution: a loss comparison," in Proceeding of the IEEE/PES Transmission and Distribution Conference and Exposition (TDCE '08), pp. 225-231, April 2008.

[3] H. Kakigano, M. Nomura, and T. Ise, "Loss evaluation of dc distribution for residential houses compared with ac system," in Proceeding of the International Power Electronics Conference (IPEC '10), pp. 480-486, June 2010.

[4] M. Mahmoodi, G. B. Gharehpetian, M. Abedi, and R. Noroozian, "A suitable control strategy for source converters and a novel load-generation voltage control scheme for DC voltage determination in DC distribution systems," in Proceeding of the 1st International Power and Energy Conference (IPEC '06), pp. 363-367, November 2006.

[5] M. Starke, F. Li, L. M. Tolbert, and B. Ozpineci, "AC versus DC distribution: maximum transfer capability," in Proceeding of the IEEE Power and Energy Society (PES '08), pp. 922-927, July 2008.

[6] A. Sannino, G. Postiglione, and M. H. J. Bollen, "Feasibility of a DC network for commercial facilities," IEEE Transactions on Industry Applications, vol. 39, no. 5, pp. 1499-1507, 2003.

[7] P. Nuutinen, P. Salonen, P. Peltoniemi, T. Kaipia, P. Silventoinen, and J. Partanen, "Implementing a laboratory development platform for an LVDC distribution system," in Proceeding of the International Conference on Smart Grid Communications (ICSGC '11), pp. 84-89, Brussels, Belgium, October 2011.

[8] G. Byeon, H. Lee, T. Yoon, G. Jang, W. Chae, and J. Kim, "A research on the characteristics of fault current of DC distribution system and AC distribution system," in Proceeding of the 8th International Conference on Power Electronics and ECCE (ICPE\&ECCE '11), pp. 543-550, June 2011.

[9] L. Tang and B.-T. Ooi, "Locating and isolating DC faults in multi-terminal DC systems," IEEE Transactions on Power Delivery, vol. 22, no. 3, pp. 1877-1884, 2007.

[10] A. Monti, M. Colciago, P. Conti, M. Maglio, and R. A. Dougal, "Integrated simulation of communication, protection, and power in MVDC systems," in Proceeding of the IEEE Electric Ship Technologies Symposium (ESTS '09), pp. 353-359, April 2009.

[11] P. Salonen, P. Nuutinen, J. Partanen, and P. Peltoniemi, "Protection scheme for an LVDC distribution system," in Proceeding of the 20th International Conference and Exhibition on Electricity Distribution (ICEED '09), pp. 1-4, June 2009.

[12] P. Salonen, P. Nuutinen, P. Peltoniemi, and J. Partanen, "LVDC distribution system protection-solutions, implementation and measurements," in Proceeding of the 13th European Conference on Power Electronics and Applications (ECPEA '09), pp. 50625071, September 2009.

[13] M. E. Baran and N. R. Mahajan, "Overcurrent protection on voltage-source-converter-based multiterminal DC distribution systems," IEEE Transactions on Power Delivery, vol. 22, no. 1, pp. 406-412, 2007.
[14] D. Wang, C. Mao, J. Lu, X. Chen, J. Zeng, and J. Zhang, “Technical analysis and design concept of DC distribution system," Automation of Electric Power Systems, vol. 37, no. 8, pp. 8288, 2013.

[15] H. Li, W. Li, M. Luo, A. Monti, and F. Ponci, "Design of smart MVDC power grid protection," IEEE Transactions on Instrumentation and Measurement, vol. 60, no. 9, pp. 30353046, 2011.

[16] S.-K. Kim, J.-H. Jeon, C.-H. Cho, E.-S. Kim, and J.-B. Ahn, "Modeling and simulation of a grid-connected PV generation system for electromagnetic transient analysis," Solar Energy, vol. 83 , no. 5, pp. 664-678, 2009.

[17] M. J. Barnes, E. Blackmore, G. D. Wait et al., "Analysis of highpower IGBT short circuit failures," IEEE Transaction Plasma Science, vol. 33, no. 4, pp. 1252-1261, 2005.

[18] H. Y. Long, N. Luther-King, M. R. Sweet, and E. M. S. Narayanan, "Numerical evaluation of the short-circuit performance of 3.3-kV CIGBT in field-stop technology," IEEE Transactions on Power Electronics, vol. 27, no. 5, pp. 2673-2679, 2012.

[19] P. Duan, K.-G. Xie, L. Zhang, and X. Rong, "Open-switch fault diagnosis and system reconfiguration of doubly fed wind power converter used in a microgrid," IEEE Transactions on Power Electronics, vol. 26, no. 3, pp. 816-821, 2011.

[20] U.-M. Choi, H.-G. Jeong, K.-B. Lee, and F. Blaabjerg, "Method for detecting an open-switch fault in a grid-connected NPC inverter system," IEEE Transactions on Power Electronics, vol. 27, no. 6, pp. 2726-2739, 2012.

[21] J. Yang, J. E. Fletcher, and J. O'Reilly, "Short-circuit and ground fault analyses and location in VSC-based DC network cables," IEEE Transactions on Industrial Electronics, vol. 59, no. 10, pp. 3827-3837, 2012. 


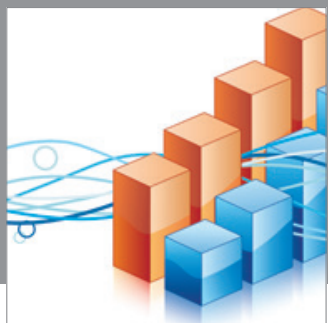

Advances in

Operations Research

mansans

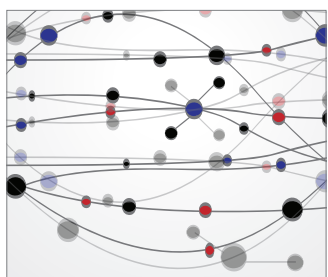

The Scientific World Journal
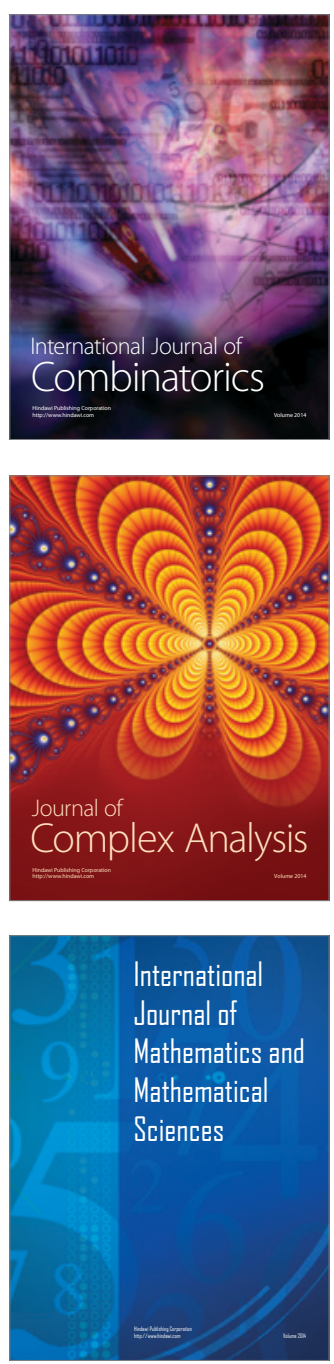
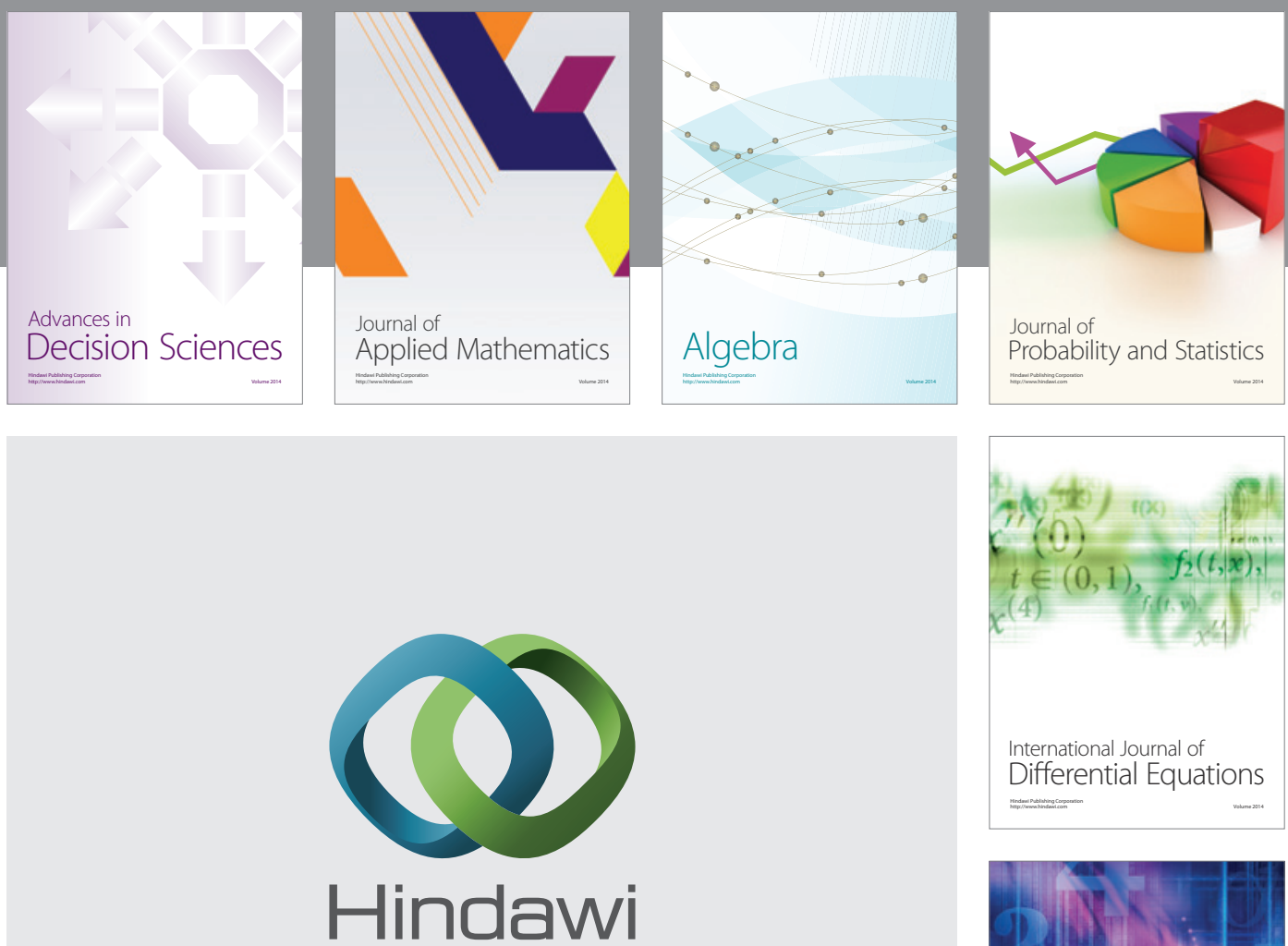

Submit your manuscripts at http://www.hindawi.com
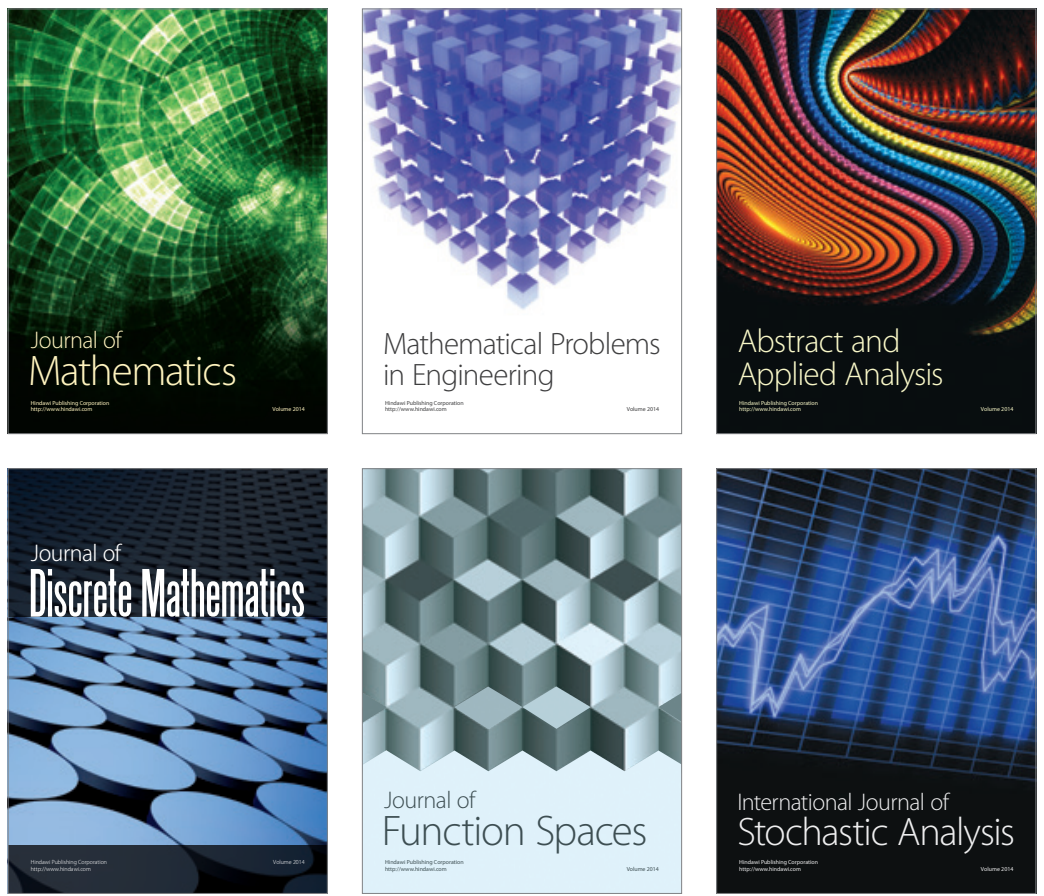

Journal of

Function Spaces

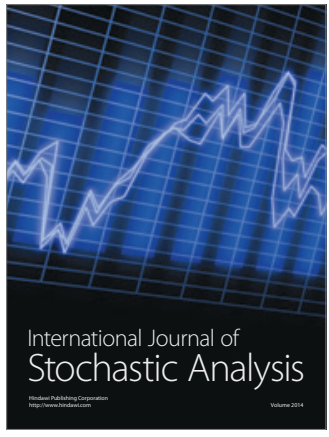

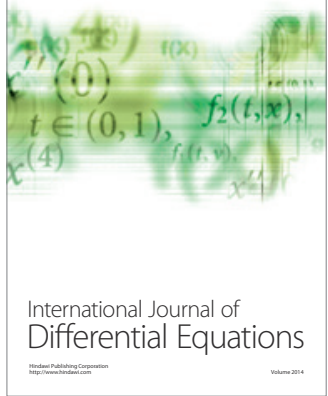
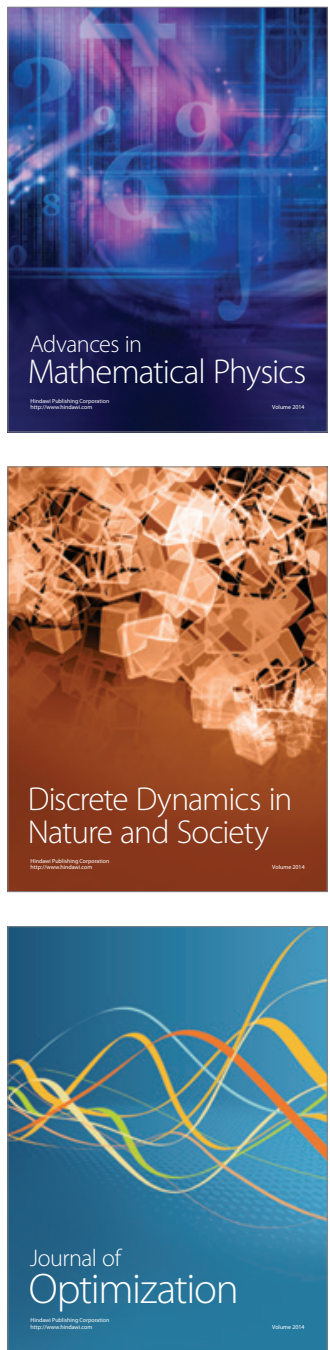